\section{WIND STRUCTURE IN THE TRADES}

$I^{\mathrm{T}}$

$\mathrm{T}$ is now forty-two years since Sir Geoffrey Taylor 1 inaugurated modern scientific study of the dynamics of wind in the lower layers of the atmosphere with his theoretical and experimental work on turbulent viscosity published in the Philosophical Transactions of the Royal Society in 1915. That work was a direct consequence of the sinking of the Titanic and 'Taylor's appointment to investigate, in the Scotia, the meteorology of the ocean area in which the Titanic sank.

The latest research on the subject is that by H. Charnock, J. R. D. Francis and P. A. Sheppard in the same series (Phil. Trans., A, No. 963, 249; Oct. 1956). These workers made 466 double-theodolite pilot balloon ascents from the island of Anegada in the West Indies in the spring of 1953. This island is in the easterly trade-wind belt. The trade winds in this area are very suitable for detailed study of wind structure because of their comparative constancy and, above all, because they decrease with height above the relatively small height of $350 \mathrm{~m}$. The decrease above this height is due to the fact that the air temperature at a fixed height increases from north to south, so that the north to south fall of pressure, giving easterly winds, decreases with height. Up to $1,000 \mathrm{ft}$. the wind increases with height because of increasing distance from the sea surface. This kind of variation of wind with height permits calculation of the drag exerted by the ocean on the wind. The value of the drag for these winds, of speed about $6 \mathrm{~m} . / \mathrm{s}$, is 0.41 dynes $/ \mathrm{cm}^{2}$, which corresponds to a drag coefficient of $1.24 \times 10^{-3}$. There were also evaluated the variation with height of the downwind and crosswind eddy stresses, the coefficient of turbulent viscosity and the eddyvelocity products.

The downwind coefficient of turbulent viscosity came out at about $1 \times 10^{5} \mathrm{~cm} .{ }^{2} / \mathrm{sec}$. and the cross. wind one about three times as great.

The eddy velocity products, $\left(u^{\prime}\right)^{2}$, etc., showed that the turbulence was not isotropic at any height in the layer, 1,350 m. deep, through which observations were made. The downwind eddy velocity variances were of the order of $50,000(\mathrm{~cm} . / \mathrm{sec} .)^{2}$, the crosswind ones about 120,000 and the vertical ones 1,200 at most. This is rather a surprising result, showing that the damping effect of the sea surface on vertical eddy movements extends to a greater height than had earlier been realized.

\section{SOME RECENT ASTRONOMY AT TOKYO}

T HE Annals of the Tokyo Astronomical Observatory (University of Tokyo. Second Series, 4, No. 3 ; 1956) contain two papers, the first of which is "Tables for the Approximate Special Perturbations by Means of the Variation of Parameters", by Tadao Takenouchi. With mean anomaly for every 10 degrees from $0^{\circ}$ to $180^{\circ}$, nine coefficients have been computed to three-decimal accuracy, except in the case of the eccentricity, where two-decimal accuracy is sufficient. The coefficients are as follows: $\alpha=$ $\cos E-e, \beta=\sin E, \gamma=-\sin E /(1-e \cos E), \delta=\cos E /$ $(1-e \cos E), \quad \lambda=-2 e \sin E, \quad \mu=(1-e \cos E)^{2}, \quad \nu=$ $-1 / \mu^{1 / 2}$.
The tables can also be adapted for the computation of ephemerides. A numerical example of their application is given.

The second paper, by Masatoshi Kitamura and Tsuyoshi Nakamura, with the title "A Photoelectric Study of the Atmospheric Extinction at Tokyo Astronomical Observatory", deals with the weakening of starlight passing through the Earth's atmosphere; this weakening is caused by absorption and scattering due to particles in the atmosphere, and the amount of extinction and its dependence on wavelength are important in the reduction of spectral photometry. Pure extinction is due to the molecules of pure air, while haze effect is caused by water vapour, dust and smoke, the amounts of these continually varying; this haze effect is conventionally known as 'dust' extinction. As the Observatory is at Mitaka, a suburb of Tokyo, local conditions require that observations should be carried out towards the west, and these were made with the photoelectric apparatus attached to the 26 -in. refractor of the Observatory, from the zenith towards the western horizon. The selected stars were $\beta$ And. and $\beta$ Tri., spectral type M0 and A5, respectively, and the observations were carried out on December $5-6$, 1955, and January 9-10, 1956. Observations were made in 1951 by T. Dambara with the same apparatus on $\alpha$ Gem. $A$ (A0), and these were placed at the disposal of the authors. All three stars pass close to the zenith at Tokyo.

The reduction of observations was based on the well-known formula $\Delta M=k \sec Z$, where $\Delta M$ is the loss of light in magnitude, and $k$ is the extinction coefficient. This varies with the wave-length of the light, and formulæ for corrections of this and other disturbing factors are provided for use in the compilation of the extinctions given in Tables $1 a, 1 b, 2 a$, $2 b, 3$ for the stars selected. The results of extinction observations, extinction coefficients and absolute humidity are shown graphically and there is a short discussion on the dust absorption $k_{D}$, the variable part of which is mostly due to the amount of watervapour, for the lower atmosphere may be considered to absorb the starlight at discrete wave-lengths. Taking into consideration all the meteorological conditions at Tokyo, it is considered that no useful results would be obtained by discussing the atmospheric extinction there from data for zenith distances greater than $60^{\circ}$.

\section{IMPACT OF INDUSTRIALIZATION ON RURAL LIFE IN THE BELGIAN CONGO}

A $\mathrm{N}$ account of the impact of industrialization on rural life in the Belgian Congo has been given by the Rev. J. E. Young, of the Baptist Missionary Society (Rural Life J., No. 10; November 1956). The developments have taken place under the guidance of the Belgian Colonial Government, and this administration has achieved a considerable degree of success, perhaps a higher degree than most of its neighbours in Africa.

Stanley's journey nearly eighty years ago revealed a vast country of enormous potential wealth. To exploit this wealth, 280 miles of railway were built from the coast, by-passing the rapids of the lower Congo. The vision and judgment of King Leopold 